\title{
Assessment of the Performance Parameters for the Side-Shift Offset Rotavator
}

\author{
Shekhar Kumar Sahu* and Kunj Bihari Tiwari \\ Department of Farm Machinery and Power Engineering, College of Agricultural \\ Engineering, Jabalpur - 482004, India \\ *Corresponding author
}

\section{A B S T R A C T}

\section{Keywords}

Instantaneous depth, Angle of blade rotation, Soil cutting force, Fuel meter

Article Info

Accepted:

04 January 2019

Available Online:

10 February 2019
The side-shift offset rotavator was a newly introduced implement in the field of interculture operations, especially for the orchard crop. The commercially available implement was equipped with $\mathbf{J}$ shape soil cutting blades. Those blades were replaced with $\mathrm{L}$ shape blades due to their undesirable outcomes. The testing was carried out separately for both types of blades at a fixed tilling depth of $9.6 \mathrm{~cm}$. In this study, the type of cutting blade, kinematic parameter and soil moisture were the considered as the explanatory parameters. Whereas, the mean weight diameter of soil, weeding efficiency, fuel consumption, theoretical torque, and cost of operation were taken as response parameters. The results revealed that the $\mathrm{L}$ shape blade produced finer soil than the $\mathbf{J}$ shape blade for the same kinematic parameter and soil moisture with the higher torque and fuel consumption. Considering the optimized value of the above parameters, the effective field capacity and cost of operation were determined as $0.12 \mathrm{ha} / \mathrm{h}$ and680 $\square / \mathrm{h}$ respectively.

\section{Introduction}

The side-shift offset rotavator is an uncommon mounted type implement. Primarily, it is used for weeding and pulverization of the soil around trees of the orchard. It has been facilitated with a mechanical sensor and an integrated hydraulic actuation system that allows the side shifting of the rotor assembly. The sensor is fixed at the front side of the rotor assembly as shown in Figure 1. It operates along the tree row under the tree canopy. During the operation, initially, its rotor remains offset rightwards and slightly ahead from the radius of the tree stem. As the tractor advances its sensor strikes with the stem and got pressed. This movement of sensor gives a signal to its integrated hydraulic system and governs the actuation of a double acting cylinder. The piston rod of the cylinder remains connected with the rotor assembly. The piston is shifted leftward which in turn the rotor assembly gets away from the tree stem. As soon as the sensor skips the tree it gets free from the pressure. It comes back on its previous position and thus, the rotor assembly also comes on its initial position. Thus, the rotor 
skips the tree and accomplishes the intra-row weeding without any damage. The comprehensive role of its geometry and the hydraulic system gives it an advantage over offset disc harrow and offset rotavator (without shifting mechanism) to perform intra-row weeding and tillage.

The above-discussed operations have to perform under the canopy of the tree. Therefore, the radius of the tree canopy must be within the offset range of the rotor assembly. In addition to this, the pruning height of the tree should be enough so that the rotor assembly can move under the canopy without any hindrance of the branches. Some of the related agronomical information of different horticultural crops is given in Table 1. This was a newly introduced technology in the field of intercultural operations so the available information about its soil pulverization quality, weeding ability, and fuel consumption was very limited. The purpose of this experiment was to evaluate its performance parameters under actual field conditions.

\section{Materials and Methods}

\section{Design of the experiment}

The full factorial design was used for assessing the performance of the side-shift offset rotavator.

\section{Preparation of the experimental field}

The experimental plot was selected from the field of Centre of Excellence in Farm Machinery, Ludhiana, Punjab. It was unploughed and no crops were grown in previous season, it was covered from small weeds and grass. From this field, the main plot of the size of $110 \times 60 \mathrm{~m}^{2}$ was selected. It was divided into 33 subplots (32 used) according to the layout of the experimentas shown in Figure 3. The area of each subplot was $10 \times 20 \mathrm{~m}^{2}$ in which the bamboo poles were placed at the spacing of $3 \times 3 \mathrm{~m}$, which was considered as the tree stem.

\section{Selection of the explanatory variables for the side-shift offset rotavator}

The soil, machine and operational parameters were selected and for assessing its performance. Respectively, from these three parameters the four levels of soil moisture content, two levels of the type of soil cutting blade (i.e. J and L-Shape blades) and four levels of the kinematic parameter ( $\lambda$-ratio) were chosen (Table 2).

\section{Procedure for attaining the different levels of the explanatory parameters}

\section{Soil moisture level}

The friable or crumbly phase of the soil has been considered as the perfect condition for tillage operations. In order to attain this range of soil moisture, first, the plot was irrigated up to the field capacity and left for sun drying so that the whole area of the experimental plot can attain uniform moisture content. The moisture level was decreased after certain hours. The soil moisture was measured periodically to meet the favourable moisture range.

The rapid moisture meter was used for determining the soil moisture content. As soon as the value of soil moisture was found near the higher level of the recommended range for the tillage operation was selected as the higher level. The soil moisture was depleted by the time due to the sun drying. Thus, its remaining levels that have lower values than the initial one were obtained by the interval of one day. Thus, four different levels of soil moisture 10.00, 12.40, 14.95, and $16.40 \%$ were selected. These are denoted by $\mathrm{M}_{1}, \mathrm{M}_{2}, \mathrm{M}_{3}$ and $\mathrm{M}_{4}$, respectively. 


\section{Soil cutting blade}

The two types of soil cutting blades were selected to investigate the tillage performance. The J-shape blades were integrated with the implement. Sahu et al., (2018) found that the J-shape blades form undesirable soil profile (ridge and valley) for tillage. Therefore, it was replaced with commercially available $\mathrm{L}$-shape blades to get rid of this issue. The notation for $\mathrm{J}$ and $\mathrm{L}$ shape soil cutting blades are given by $\mathrm{B}_{1}$ and $\mathrm{B}_{2}$, respectively.

\section{Kinematic parameter ( $\lambda-$ ratio or $\mathrm{u} / \mathrm{v}$ ratio)}

The kinematic parameter is the ratio of the peripheral speed of the rotor $(\mathrm{m} / \mathrm{s})$ to the forward speed of the travel $(\mathrm{m} / \mathrm{s})$. The four different levels of the kinematic parameters $8.86,7.01,5.60$ and 4.80 were attained by increasing the forward speed of the travel respectively $1.90,2.41,3.02$ and $3.53 \mathrm{~km} / \mathrm{h}$. While the peripheral speed, rotational speed and diameter of the rotor, were kept constant as $4.7 \mathrm{~m} / \mathrm{s}, 280 \mathrm{rpm}$ and $320 \mathrm{~mm}$, respectively. The depth of the operation was set at $9.6 \mathrm{~cm}$. The levels of the kinematic parameters are coded by $\lambda_{1}, \lambda_{2}, \lambda_{3}$, and $\lambda_{4}$, respectively.

\section{Determination of the parameters}

\section{Forward speed of the operation}

The tractor equipped with the side-shift rotavator was set few meters away from the first bamboo pole so that the tractor and rotor can establish their forward and rotational speeds, respectively when it reaches to the pole. As soon as the sensor strikes with the first pole the stopwatch was started and when reaches to the last poleit was stopped. The time required for travelling the known distance was measured and the forward speed was determined by the equation- $V_{\mathrm{f}}=\mathrm{S} / \mathrm{t}$.
Where, $V_{f}$ is the forward speed of the travel, $(\mathrm{m} / \mathrm{s}) ; \mathrm{S}$ is the linear distance travelled by the rotor or tractor, $(\mathrm{m})$; and $\mathrm{t}$ is the time required to travel the distance (s).

\section{Rotational speed of the blade rotor}

The speed of the rotor was measured at the outermost flange with the help of a noncontacting type tachometer. The rotor speed was varied and measured until it attained the constant speed of 280 RPM. The rotor speed was taken the same for all four levels of the kinematic parameter.

\section{Testingprocedure for the side-shift offset rotavator}

First of all, the field was prepared as discussed in Article 2.1. The side-shift offset rotavator was equipped with a tractor and set along the row of trees. The right end of the rotor assembly was kept little ahead from trunk radius of the tree and then driven by PTO shaft without engaging it into the soil. Thereafter, it was penetrated in the soil by pushing down through the hydraulic system of the tractor. The tractor was moved forward in order to accomplish intra-row weeding. The rotating blade started to cut the soil as well as weeds. The pictorial view of the working of side shift offset rotavator is given in Figure 2.

\section{Mean weight diameter}

The particle size of tilth soil obtained after operating the side-shift offset rotavator is the measures of the seedbed quality. The finer grain size of soil represents the good quality of a seedbed. The grain size of the pulverized soil was determined through sieve analyzer and given by the mean weight diameter.

The side-shift offset rotavator was operated on the experimental field at different 
combinations of cutting blades, soil moisture content and $\lambda$-ratio. Thereafter the soil samples were collected from the area of $15 \times 15 \mathrm{~cm}^{2}$ at operating depth. The collected samples were dried in hot air oven dryer for 24 hours at $105{ }^{\circ} \mathrm{C}$. The set of sieves of a mechanical sieve shaker were arranged in descending order $(4.75 \mathrm{~mm}, 2.36 \mathrm{~mm}$, $1.18 \mathrm{~mm}, 600 \mu, 300 \mu, 150 \mu, 75 \mu$ and pan, Fig. $3)$. From the dried sample, $800 \mathrm{~g}$ soil was taken and filled in the top sieve. The sieves were shaken through a motor for 10 minutes so that the soil particles can pass through the oversize sieve and retained on the undersize sieve. The retained soil of the particular sieve was collected and weighed. The mean weight diameter of the soil was calculated by the following equation (Kemper and Rosenau, 1986)-

$M W D=\sum_{i=1}^{n} \bar{X}_{i} W_{i} \ldots 1$

Where, $\overline{X_{2}}$ is the mean dia. of the sieves at which soil retained and previous sieve, $\mathrm{mm}$; and $W_{i}$, is the fraction of weight of soil collected from the retained sieve to the total weight of the sample, $g$

\section{Weeding efficiency}

Removal of the weeds between the trees was theprimarypurpose of the side-shift offset rotavator. The weeding efficiency was the important criterion for evaluating its performance. The weeding efficiency was determined by the following equation.

$\eta_{\mathrm{w}}=\left(\mathrm{W}_{\mathrm{b}}-\mathrm{W}_{\mathrm{a}}\right) / \mathrm{W}_{\mathrm{b}} \times 100 \%$

Where $\mathrm{W}_{\mathrm{b}}$ and $\mathrm{W}_{\mathrm{a}}$ are the dry weight of weeds collected from the field before and after the operation. The subplots were tilth using the side-shift offset rotavator, which cut the weeds. Thereafter, a square ring of the size of $30 \times 30 \mathrm{~cm}^{2}$ was placed randomly on the tilth area. The cut weed lied under this ring was collected, while the uncut weeds were uprooted manually and collected separately. The collected cut and uncut weeds were dried in oven dryer for 24 hours. The dry weight of cut weeds and uncut weeds $\left(\mathrm{W}_{\mathrm{a}}\right)$ was the total weight of weeds per square meter abbreviated as $\mathrm{W}_{\mathrm{b}}$. The values of weeding efficiency are given in Table 4.

\section{Fuel consumption}

A flow meter device was used to measure the fuel consumed by the side-shift offset rotavator during the operation at different soil condition. The range of measurement of the flow meter was 0.5 to $25.0 \mathrm{l} / \mathrm{h}$. In order to attach the flow meter with the fuel supply system of the tractor engine, its input hose was connected to the output hose of the fuel delivery line as shown in Figure 4. The output of flow meter was connected with a $\mathrm{T}$-joint whose lateral hose deliver the fuel to the engine through a pipe. The fuel which passes through the lateral hose was measured by the flow meter which shows the consumption of diesel fuel for the total operating time. The unused diesel which returned back through the return line was joined with the longitudinal hose of the T-joint. Thus, the part of premeasured fuel doesn't go back into the fuel tank or to the flow meter. The measured quantity of fuel at different levels is given in Table 4.

It is a general behaviour observed by many researchers that the physical properties of the soil like bulk density and cone index, and moisture content, affects the tillage performance. Since these properties were determined by following the standard procedure. The bulk density and cone index were determined using standard procedure IS: 2720(29)-1975 and IS: 2720-1986 
respectively. While the moisture content of the soil was measured by the rapid moisture meter.

\section{Results and Discussion}

The average values of the soil bulk density, cone index and moisture content was determined as $1722 \mathrm{~kg} / \mathrm{m}^{3}, 898 \mathrm{kN} / \mathrm{m}^{2}$ and $13.44 \%$ respectively. It was found that the bulk density of the soil does not have a direct relationship with the soil moisture. It was also observed that the penetration resistance increases with the bulk density of the soil.

The average values of mean weight diameter for both the cutting blades were plotted against the soil moisture content as represented in Figure 5. This figure reveals that the diameter of the soil particle possesses a positive correlation with the moisture content. Initially, it was found to be smaller at lower moisture because of a decrease in cohesion force which readily breaks by the impact of the blade. As the moisture increases the bond become stronger which resulted in larger diameter.

It is revealed from Figure 6 that the kinematic parameter inversely influences the mean weight diameter of the soil. In the beginning, the particle diameter was found to be larger at a lower value of the kinematic parameter. Since, in this case, the smaller value of the kinematic parameter represents the higher forward speed. It causes a longer cut of soil which forms bigger clods. Its vice-versa is also true, contrarily; the clod diameter was decreased with the kinematic parameter.

\section{Fuel consumption}

The fuel consumption was found to be decreased as with the moisture content as shown in Figure 7. The possible reason might be the reduced soil strength which allows ready penetration of the blade. This cause reduction in the cutting force and consequently the engine requires to produce lesser power which directly affects the fuel consumption.

The fuel consumption confirmations the inverse relation with the kinematic parameter as represented in Figure 8. It might be due to the fact that the reduced value of the kinematic parameter increases the rate of throw of the soil mass. The increased workload causes the engine requires to produce higher power and consequently the fuel consumption was increased.

\section{Estimation of the theoretical torque required for the blade}

The 'L-shape' blade has two parts, respectively, the vertical part and horizontal, named as leg and span. Both the portion of the blade inserts into the soil and requires certain force to overcome useful (cutting and throwing of soil) and frictional forces. A model was given by Marenya et al (2003), Marenya and du Plessis (2006), and Marenya (2009). They explained in their models that the torque required to overcome these forces varies with the penetration of blade. For a fixed depth of operation, the penetration of blade into the soil varies with respect to the angle of rotation of the blade. In this study, these models were adopted for estimating the theoretical torque required by the blade. The programs were written in the MATLAB software by using the adopted models to describe the nature of the torque with respect to the angle of rotation of the blade.

The movement of a single blade into the soil is schematically shown in Figure 9. This figure explains that the blade started to enter into the soil profile at an angle of $23.54^{\circ}$ and exits at an angle of $94.70^{\circ}$, respectively for 16 $\mathrm{cm}$ radius of the rotor set at $9.6 \mathrm{~cm}$ depth of 
operation. When two consecutive blades of thesame flange cut the soil then a prismatic shape of soil wedge is formedas shown in figure 10 . The geometry of cut soil mass majorly depends on the depth of cut, the speed of forward travel and speed of the rotor.

In this figure, $\mathrm{L}_{\mathrm{b}}, \mathrm{W}_{\mathrm{c}}, \mathrm{d}_{\mathrm{c}}$, and $\mathrm{L}_{\mathrm{tr}}$ represents the bite-length, width of cut, depth of cut and length of tilling route respectively. The relationship between of angle of penetration of blade and torque required to cut the soil is represented in figure 11 . It reflects that the torque required to cut the soil slice increases with the angle of rotation of the blade. Initially, at a blade angle of $23.54^{\circ}$, the cutting force was found to be minimal and it increases till the exit point $\left(94.70^{\circ}\right.$ blade angle). This could be due to the increase in the depth of penetration of the blade with the angle of rotation.

Table.1 Tree spacing, canopy diameter, pruning height, trunk diameter and season of weeding of different horticultural crops

\begin{tabular}{|l|c|c|c|c|c|}
\hline Name of crop & $\begin{array}{c}\text { Tree spacing, } \\
\text { m x m }\end{array}$ & $\begin{array}{c}\text { Canopy } \\
\text { diameter, } \\
\text { m }\end{array}$ & $\begin{array}{c}\text { Pruning } \\
\text { height, } \\
\text { cm }\end{array}$ & $\begin{array}{c}\text { Trunk } \\
\text { dia., } \\
\text { cm }\end{array}$ & \multicolumn{1}{|c|}{ Season of weeding } \\
\hline Apple & $5 \times 5,4 \times 4$ & $3.5-4$ & 100 & 25 & $\begin{array}{l}\text { May-July and early in } \\
\text { spring }\end{array}$ \\
\hline Sweet orange & $6 \times 6$ & $4-4.2$ & 45 & $15-20$ & - \\
\hline Orange & $6 \times 6$ & $3-3.5$ & 45 & $20-25$ & Repeat in every 120 days \\
\hline Lemon & $5 \times 5$ & $3.6-4$ & 45 & $15-25$ & - \\
\hline Kinnow & $7 \times 7,4 \times 4$ & $3-3.85$ & 30 & $15-25$ & - \\
\hline Guava & $6 \times 6,5 \times 5$ & $3-3.5$ & $60-90$ & 25 & Rainy season \\
\hline Litchi & $8 \times 8$ & $5.5-6$ & 45 & $15-25$ & Repeat in every 2 months \\
\hline Mango & $12 \times 12,10 \times 10$ & $6-8$ & 75 & $25-40$ & Pre and post monsoon \\
\hline Pomegranate & $5 \times 5,4 \times 4$ & $2.5-3$ & $60-100$ & $15-20$ & - \\
S & $10 \times 10$ & $3-4$ & 100 & $25-40$ & \\
\hline Sapota & & & & & - \\
\hline
\end{tabular}

Source: National Horticultural Board, Ministry of Agriculture and Farmers welfare, Govt. of India

Table.2 List of explanatory variables, their notation, unit and operating levels

\begin{tabular}{|c|c|c|c|c|c|c|c|}
\hline S. no. & Name of variable & Notation & Unit & \multicolumn{4}{|c|}{ Level } \\
\hline 1 & Type of soil cutting blade & B & - & $\mathbf{J}$ & $\mathrm{L}$ & - & - \\
\hline 2 & Moisture content of soil & M & $\%$ & 10.00 & 12.40 & 14.95 & 16.40 \\
\hline 3 & Kinematic parameter $(\lambda$-ratio $)$ & $\lambda$ & - & 8.86 & 7.01 & 5.60 & 4.80 \\
\hline
\end{tabular}

Table.3 List of response variables, their notation and unit

\begin{tabular}{|l|l|c|c|}
\hline S. no. & Name of variable & Notation & Unit \\
\hline $\mathbf{1}$ & Mean weight diameter of soil & $\mathrm{D}_{\mathrm{MM}}$ & $\mathrm{mm}$ \\
\hline $\mathbf{2}$ & Weeding efficiency & $\eta_{\mathrm{w}}$ & $\%$ \\
\hline $\mathbf{3}$ & Fuel consumption & $\mathrm{FC}$ & $\mathrm{l} / \mathrm{h}$ \\
\hline
\end{tabular}


Table.4 Mean weight diameter, weeding efficiency and fuel consumption for the side -shift offset rotavator at the different blade, soil moisture content and kinematic parameter $(\lambda-$ ratio)

\begin{tabular}{|c|c|c|c|c|c|c|}
\hline \multirow{2}{*}{$\begin{array}{c}\text { No. of } \\
\text { experiment } \\
\quad s\end{array}$} & \multicolumn{3}{|c|}{ Explanatory parameters } & \multicolumn{3}{|c|}{ Response parameters } \\
\hline & $\begin{array}{l}\text { Shape } \\
\text { of blade }\end{array}$ & $\begin{array}{l}\text { Moisture } \\
\text { content, \% }\end{array}$ & $\begin{array}{c}\lambda- \\
\text { ratio }\end{array}$ & $\begin{array}{c}\text { Mean } \\
\text { weightdiamet } \\
\text { er, mm }\end{array}$ & $\begin{array}{l}\text { Weeding } \\
\text { efficiency, \% }\end{array}$ & $\begin{array}{c}\text { Fuel } \\
\text { consumption, } 1 / \mathrm{h}\end{array}$ \\
\hline 1 & $\mathrm{~B}_{2}$ & $\mathrm{M}_{3}$ & $\lambda_{4}$ & 1.207 & 100.0 & 3.32 \\
\hline 2 & $\mathrm{~B}_{1}$ & $\mathrm{M}_{3}$ & $\lambda_{3}$ & 1.293 & 100.0 & 3.14 \\
\hline 3 & $\mathrm{~B}_{1}$ & $\mathrm{M}_{1}$ & $\lambda_{3}$ & 0.413 & 100.0 & 3.26 \\
\hline 4 & $\mathrm{~B}_{1}$ & $\mathrm{M}_{4}$ & $\lambda_{1}$ & 0.836 & 100.0 & 2.49 \\
\hline 5 & $\mathrm{~B}_{1}$ & $\mathrm{M}_{1}$ & $\lambda_{2}$ & 0.271 & 91.66 & 3.14 \\
\hline 6 & $\mathrm{~B}_{2}$ & $\mathrm{M}_{4}$ & $\lambda_{3}$ & 1.266 & 100.0 & 3.19 \\
\hline 7 & $\mathrm{~B}_{2}$ & $\mathrm{M}_{1}$ & $\lambda_{3}$ & 0.308 & 100.0 & 3.38 \\
\hline 8 & $\mathrm{~B}_{2}$ & $\mathrm{M}_{4}$ & $\lambda_{1}$ & 0.777 & 88.88 & 3.00 \\
\hline 9 & $\mathrm{~B}_{2}$ & $\mathrm{M}_{4}$ & $\lambda_{4}$ & 1.533 & 85.71 & 3.30 \\
\hline 10 & $\mathrm{~B}_{1}$ & $\mathrm{M}_{4}$ & $\lambda_{2}$ & 0.837 & 85.71 & 2.66 \\
\hline 11 & $\mathrm{~B}_{2}$ & $\mathrm{M}_{2}$ & $\lambda_{3}$ & 0.316 & 100.0 & 3.27 \\
\hline 12 & $\mathrm{~B}_{2}$ & $\mathrm{M}_{3}$ & $\lambda_{3}$ & 0.879 & 90.00 & 3.26 \\
\hline 13 & $\mathrm{~B}_{1}$ & $\mathrm{M}_{2}$ & $\lambda_{3}$ & 0.481 & 87.50 & 3.18 \\
\hline 14 & $\mathrm{~B}_{1}$ & $\mathrm{M}_{3}$ & $\lambda_{4}$ & 1.701 & 75.00 & 3.23 \\
\hline 15 & $\mathrm{~B}_{1}$ & $\mathrm{M}_{3}$ & $\lambda_{2}$ & 1.031 & 100.0 & 2.93 \\
\hline 16 & $\mathrm{~B}_{1}$ & $\mathrm{M}_{2}$ & $\lambda_{4}$ & 0.669 & 88.88 & 3.23 \\
\hline 17 & $\mathrm{~B}_{1}$ & $\mathrm{M}_{1}$ & $\lambda_{1}$ & 0.261 & 100.0 & 3.09 \\
\hline 18 & $\mathrm{~B}_{1}$ & $\mathrm{M}_{4}$ & $\lambda_{4}$ & 2.087 & 100.0 & 3.06 \\
\hline 19 & $\mathrm{~B}_{2}$ & $\mathrm{M}_{2}$ & $\lambda_{4}$ & 0.455 & 83.33 & 3.41 \\
\hline 20 & $\mathrm{~B}_{2}$ & $\mathrm{M}_{3}$ & $\lambda_{2}$ & 0.616 & 100.0 & 3.15 \\
\hline 21 & $\mathrm{~B}_{2}$ & $\mathrm{M}_{2}$ & $\lambda_{2}$ & 0.264 & 100.0 & 3.21 \\
\hline 22 & $\mathrm{~B}_{2}$ & $\mathrm{M}_{3}$ & $\lambda_{1}$ & 0.556 & 100.0 & 3.08 \\
\hline 23 & $\mathrm{~B}_{2}$ & $\mathrm{M}_{1}$ & $\lambda_{1}$ & 0.225 & 100.0 & 3.12 \\
\hline 24 & $\mathrm{~B}_{2}$ & $\mathrm{M}_{1}$ & $\lambda_{2}$ & 0.231 & 100.0 & 3.20 \\
\hline 25 & $\mathrm{~B}_{2}$ & $\mathrm{M}_{2}$ & $\lambda_{1}$ & 0.239 & 100.0 & 3.13 \\
\hline 26 & $\mathrm{~B}_{1}$ & $\mathrm{M}_{2}$ & $\lambda_{1}$ & 0.280 & 100.0 & 2.98 \\
\hline 27 & $\mathrm{~B}_{1}$ & $\mathrm{M}_{4}$ & $\lambda_{3}$ & 1.600 & 100.0 & 2.78 \\
\hline 28 & $\mathrm{~B}_{1}$ & $\mathrm{M}_{2}$ & $\lambda_{2}$ & 0.336 & 100.0 & 3.11 \\
\hline 29 & $\mathrm{~B}_{1}$ & $\mathrm{M}_{1}$ & $\lambda_{4}$ & 0.722 & 84.61 & 3.31 \\
\hline 30 & $\mathrm{~B}_{2}$ & $\mathrm{M}_{4}$ & $\lambda_{2}$ & 0.829 & 75.00 & 3.06 \\
\hline 31 & $\mathrm{~B}_{1}$ & $\mathrm{M}_{3}$ & $\lambda_{1}$ & 0.794 & 100.0 & 2.81 \\
\hline 32 & $\mathrm{~B}_{2}$ & $\mathrm{M}_{1}$ & $\lambda_{4}$ & 0.359 & 75.00 & 3.45 \\
\hline
\end{tabular}


Fig.1 Illustration of the working of side-shift offset rotavator

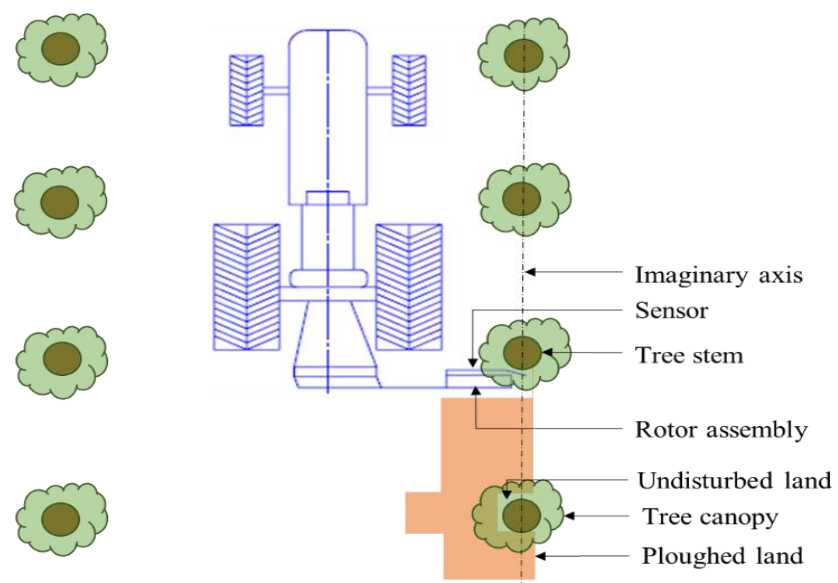

Fig.2 An operational view of the side-shift offset rotavator

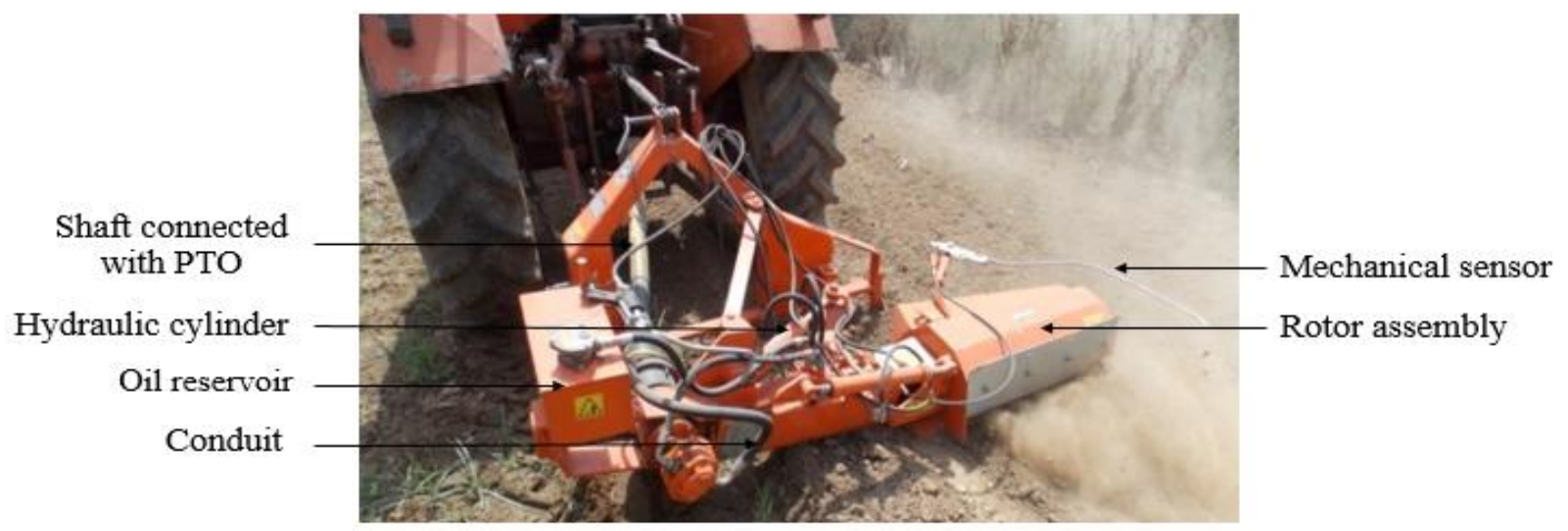

Fig.3 Motorized sieve shaker used for sieving the pulverized soil sample

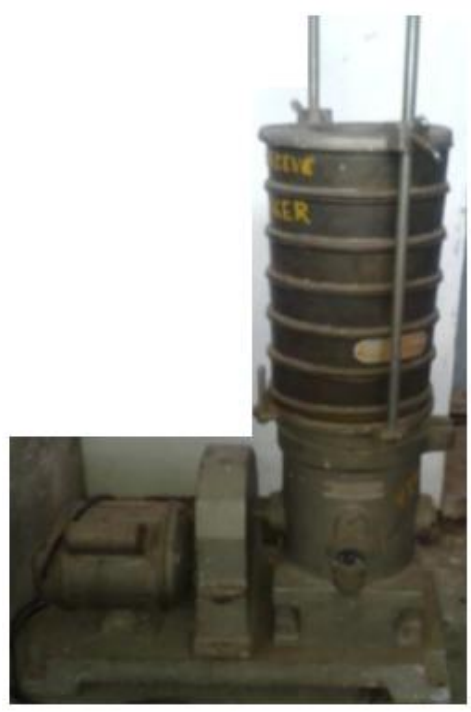


Fig.4 Attachment of fuel meter between the fuel line and engine of the tractor
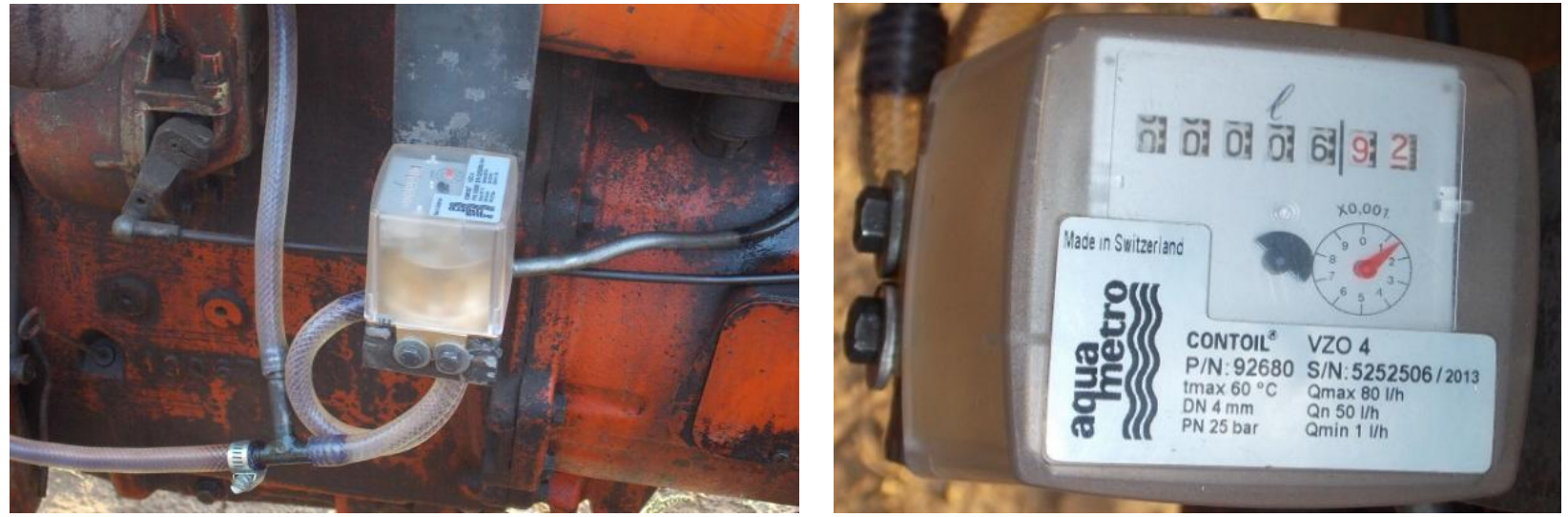

Fig.5 Variation in mean weight diameter of the soil with moisture content

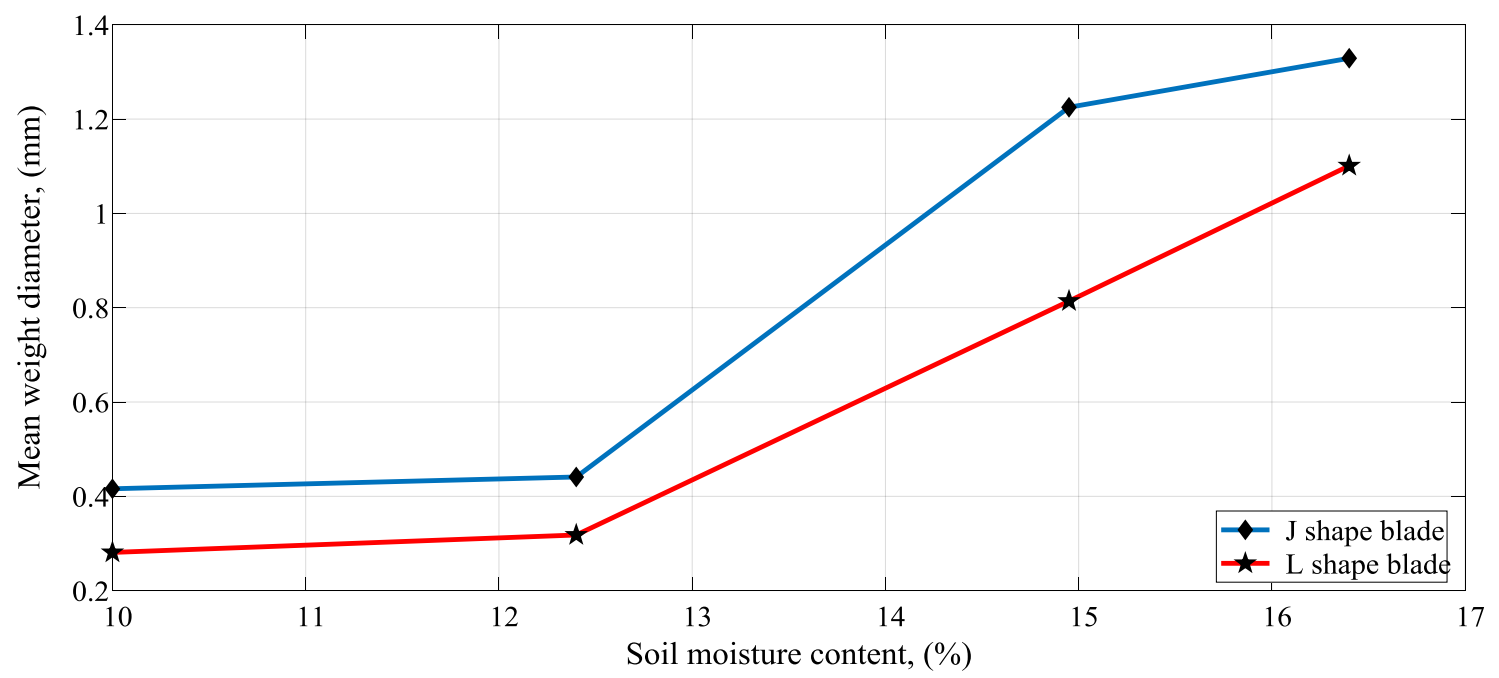

Fig.6 Variation in Mean weight diameter of the soil with kinematic parameter $(\lambda$-ratio)

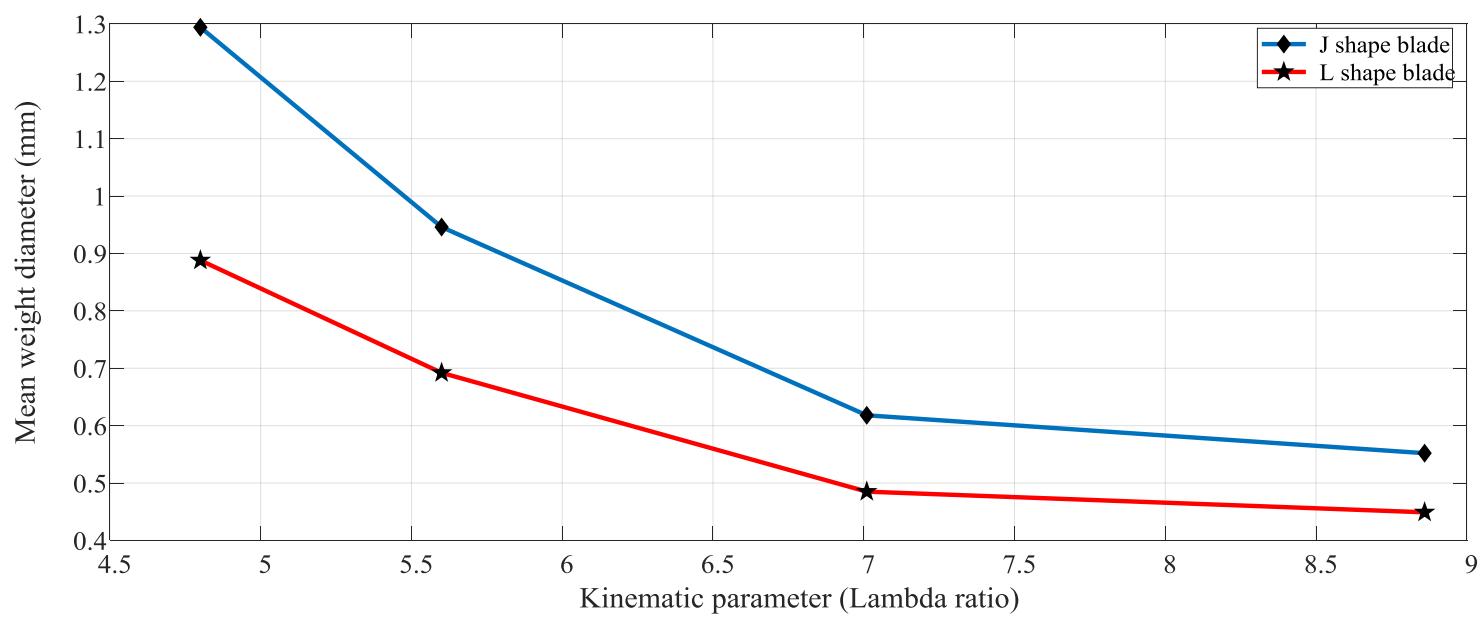


Fig.7 Variation in fuel consumption with a moisture content of the soil

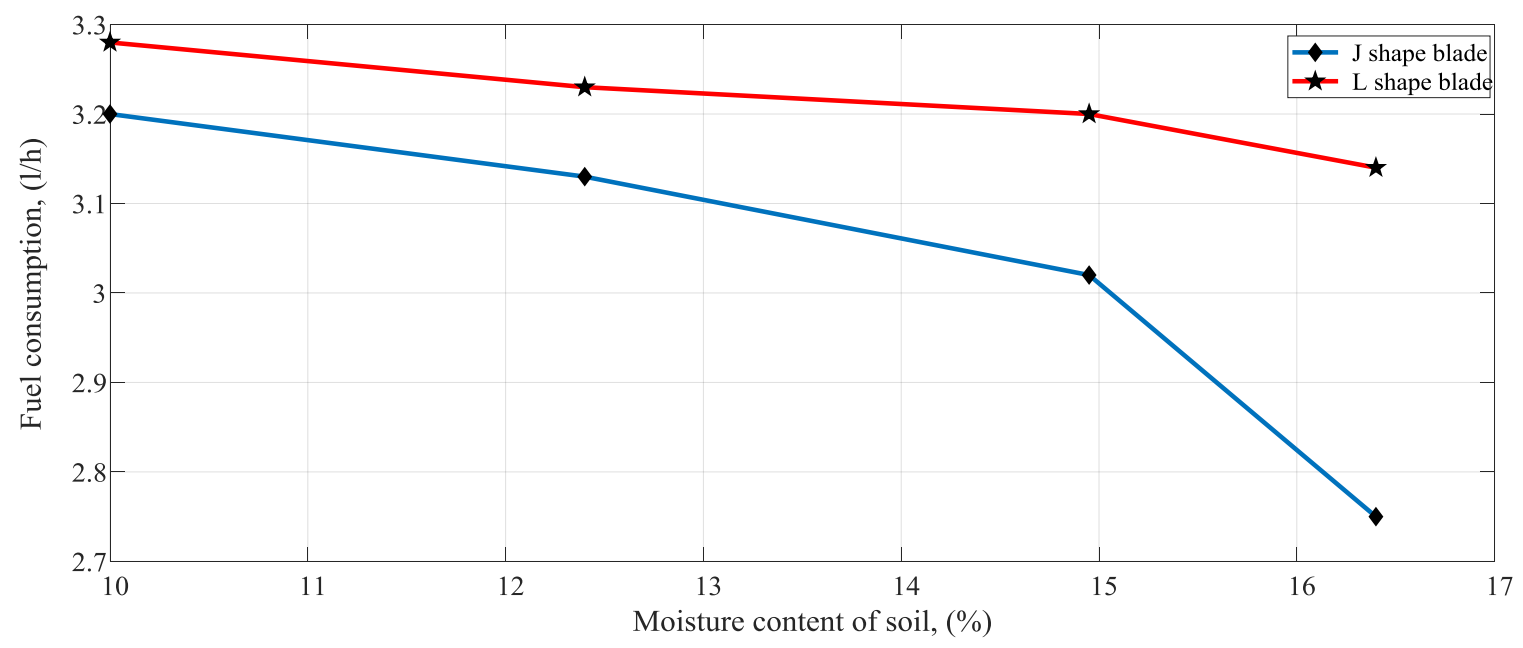

Fig.8 Variation in fuel consumption with kinematic parameter $(\lambda$-ratio)

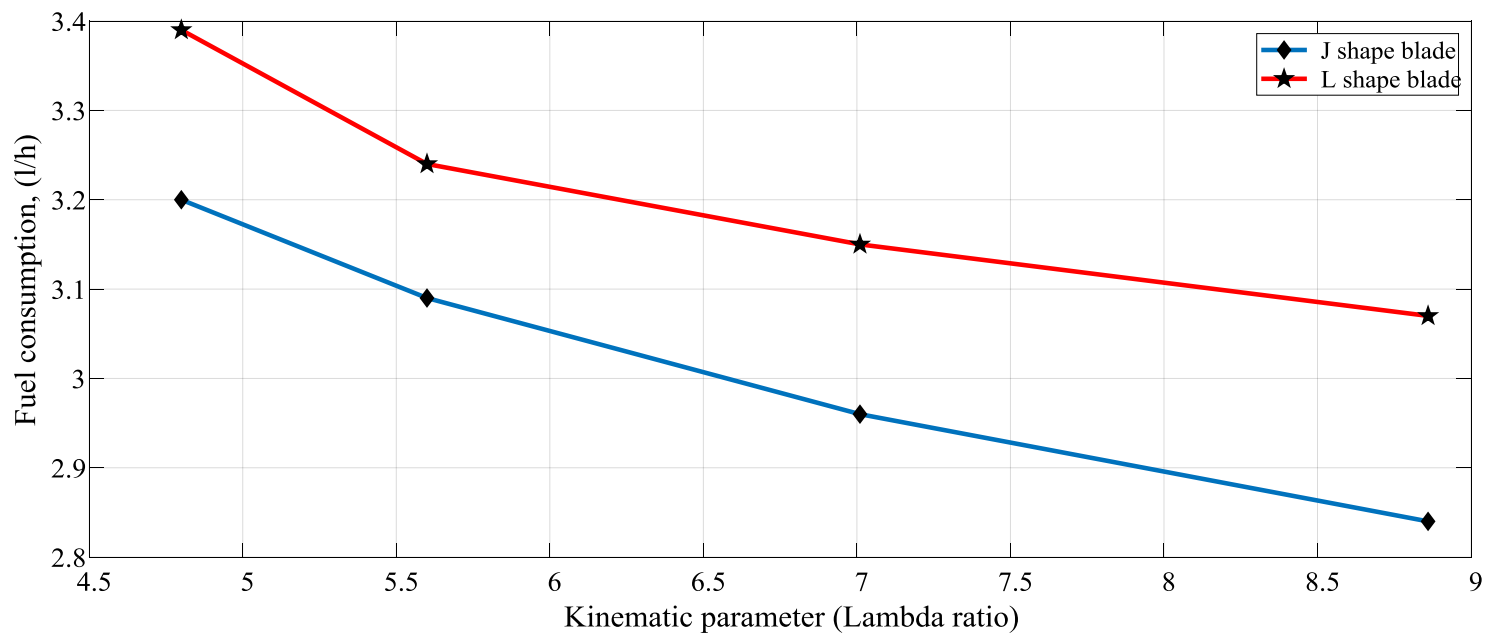

Fig.9 A typical schematic view of the movement of a single blade into the soil

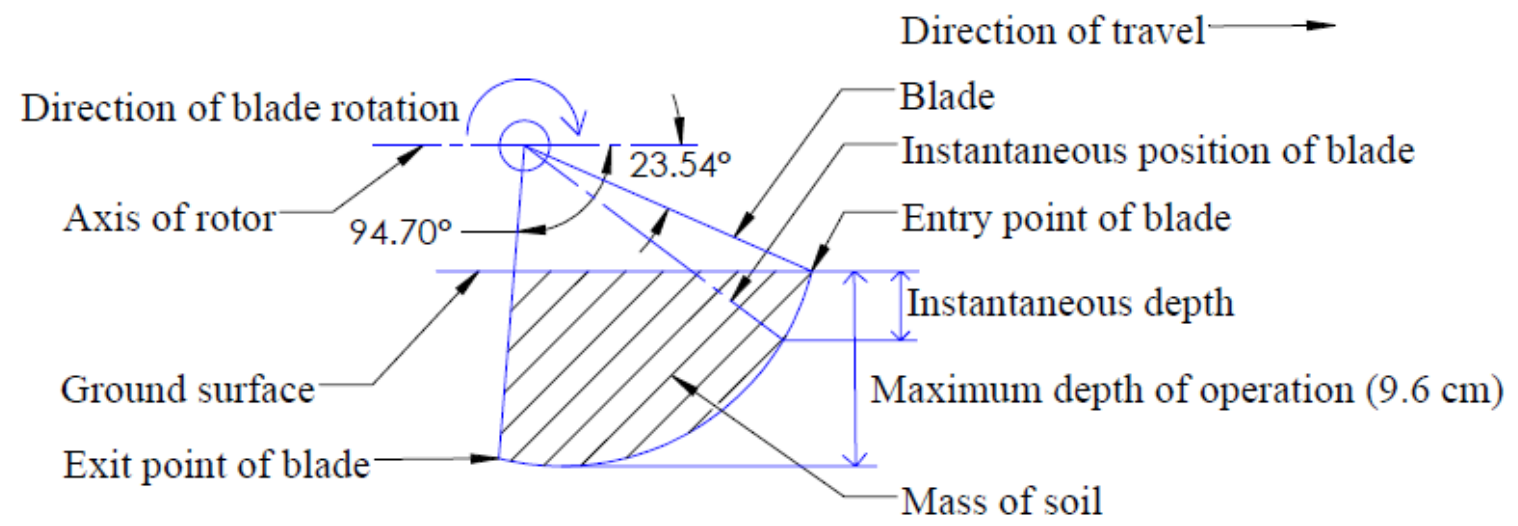


Fig.10 Schematic view of the soil slice cut by the rotor blade

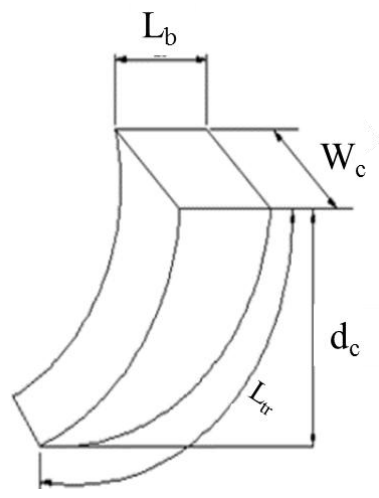

Fig.11 Torque required by the leg of the blade to cut the soil slice

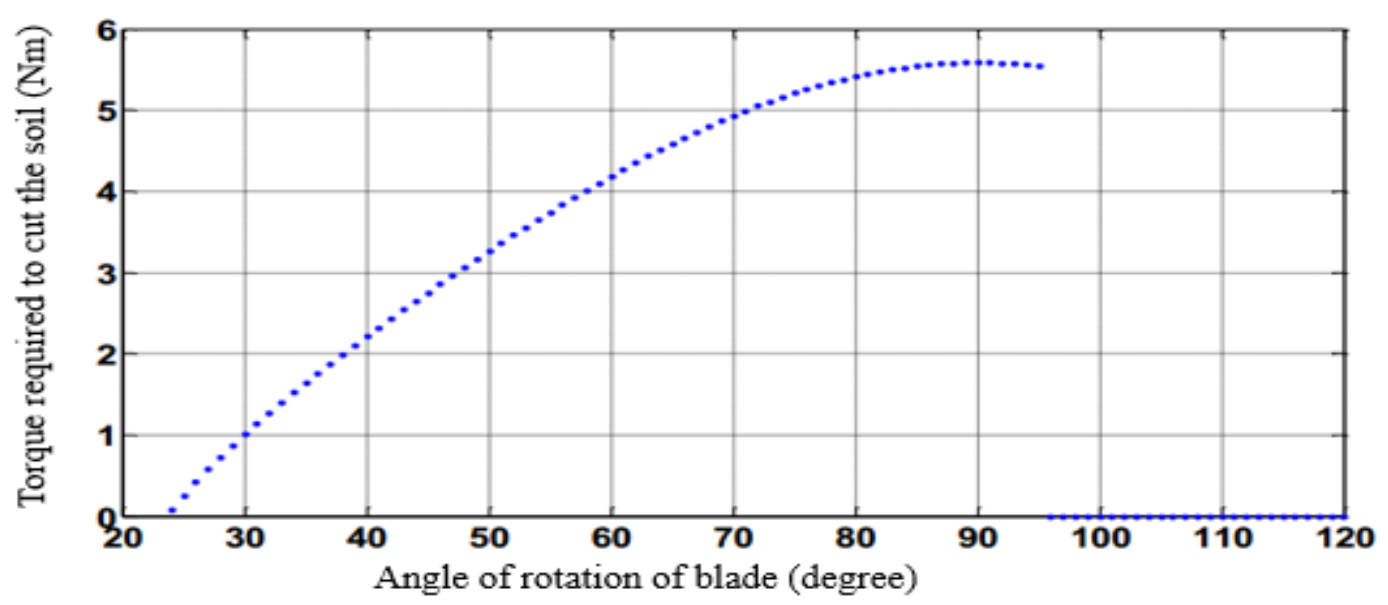

Fig.12 Torque required by the leg of the blade to overcome frictional forces

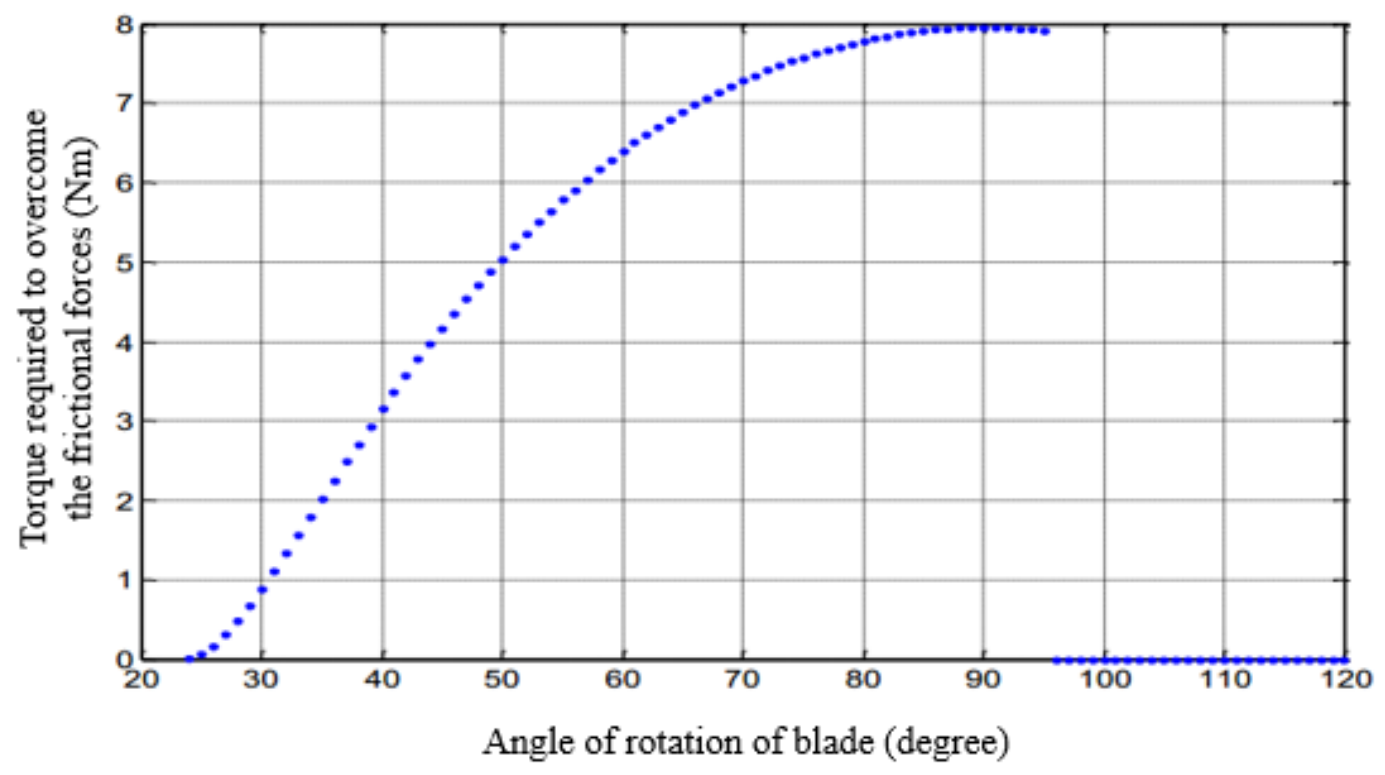


Fig.13 Torque required by the span of the cutting blade to throw the cut soil slice

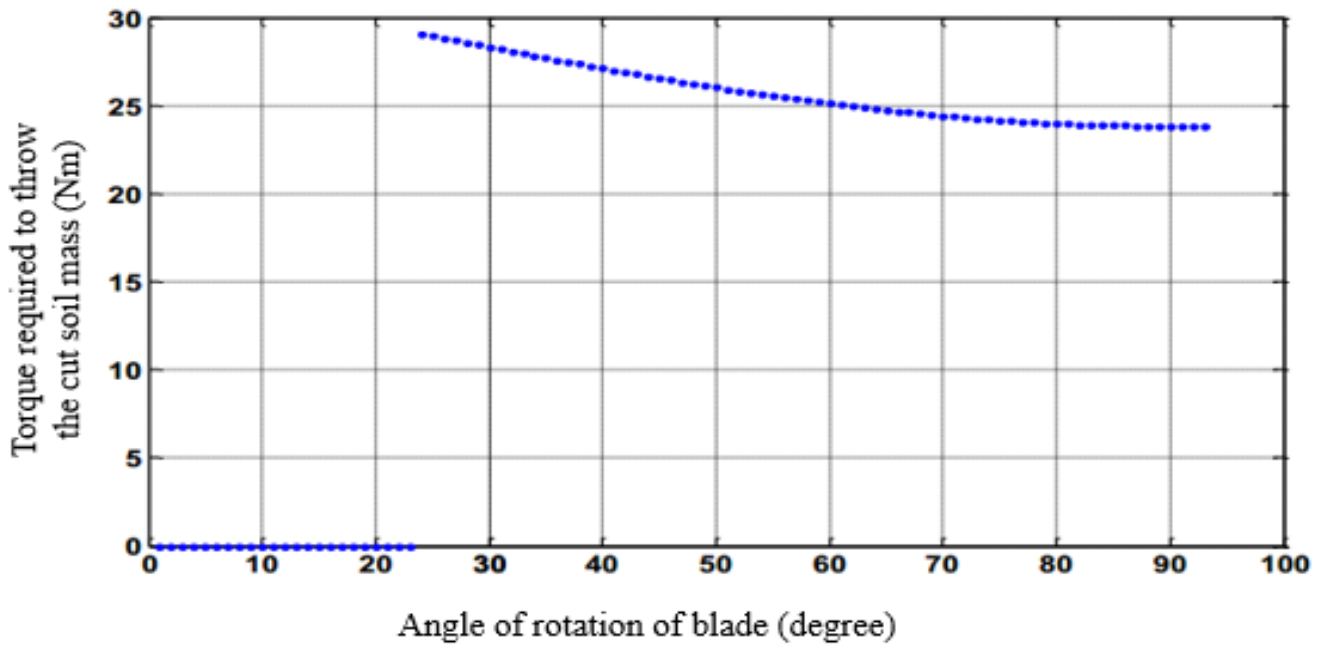

The active earth pressure increases with the depth and makes the soil more compacted which increases its strength. That is why, in order to make a deeper cut into the soil, the blade requires higher force. The peak of this torque was predicted at the maximum depth of cut $(9.6 \mathrm{~cm})$. At this position, the blade shows the highest magnitude of force/torque required to cut the soil for the maximum set tillage depth. The sudden drop of force requirement becomes zero because beyond this angle the blade moves in the soil mass which was already cultivated. The strength of pulverized soil is negligible which offers almost zero resistance to cut.

The torque required to overcome the frictional forces is depicted in Figure 12. The blade moves in the soil produce some parasitic forces. During its motion, it has to overcome from soil-soil, soil-metal frictional forces. These forces highly depend on the soil type, soil moisture content, and tool's surface roughness and contact area. As the penetration increases the contact area also increases and therefore the frictional forces also increase. It attains the maximum value at its maximum depth of operation and then sudden decreases because of friction applied by loose soils.
The force required to throw the cut soil mass was found to be reduced with the angle of rotation of the blade. Initially, it was maximum at the entrance $\left(23.54^{\circ}\right)$ because at this point the thickness of soil slice was maximum (Fig. 13) therefore the mass of soil. It reduces beyond this angle and found to be minimum at the exit point of the blade $\left(94.70^{\circ}\right)$. The reason behind that was the reduced thickness of soil slice (Fig. 13) and hence the mass. Therefore, the lower amount of force required to throw the reduced mass of soil.

The mean weight diameter of soil for the side -shift offset rotavator equipped with $\mathrm{L}$ shape blade was about 50\% higher than J shape blade at $10 \%$ soil moisture (Table 3 ). This difference was reduced up to $20 \%$ at $16.40 \%$ soil moisture. The MWD of soil was lower about $23 \%$ for $\mathrm{L}$ shape blade as compared to $\mathrm{J}$ shape blade at $8.86 \lambda$-ratio. This difference was increased by $46 \%$ at $4.80 \lambda$-ratio. The difference in fuel consumption was negligible for both the blades at the initial level of soil moisture, but it was found about $15 \%$ higher in $\mathrm{L}$ shape blade at $16.40 \%$ soil moisture. While considering the $\lambda$-ratio, it was concluded that the difference in fuel consumption was not much substantial at its 
distinct levels.

\section{References}

Kemper, W.D. and Rosenau, R.C., 1986. Aggregate stability and size distribution.

Marenya, M. O. 2009. Performance characteristics of a deep tilling rotavator. Unpublished $\mathrm{Ph}$. D. thesis. Department of Civil and Biosystems Engineering, University of Pretoria. Pretoria, South Africa.

Marenya, M. O. and du Plessis H. L. M., 2006. Torque requirements and forces generated by a deep tilling down-cut rotary tiller. ASAE Paper No. 061096. St. Joseph, Mich.: ASABE.
Marenya, M.O. du Plessis H.L.M. and Musonda N.G. 2003. Theoretical force and power 10 prediction models for rotary tillers - a review. Journal of Engineering in Agriculture and 11 the Environment, 3(1): 1-10.

National Horticultural Board, 2017. Ministry of Agriculture and Farmers welfare, Govt. of India.

Shekhar Kumar Sahu, Kunj Bihari Tiwari, Prateek Shrivastava and Rohit Namdeo. 2018. Optimization of the Kinematic Parameter and Fuel Consumption for the Side-Shift Offset Rotavator Using L and J-Shape Soil Cutting Blades. Int.J.Curr.Microbiol.App.Sci. $\quad 7(08)$ : 1970-1982.

\section{How to cite this article:}

Shekhar Kumar Sahu and Kunj Bihari Tiwari. 2019. Assessment of the Performance Parameters forthe Side-Shift Offset Rotavator. Int.J.Curr.Microbiol.App.Sci. 8(02): 287-299. doi: https://doi.org/10.20546/ijcmas.2019.802.034 